\title{
Strategic Use of Social Media in Tourism Marketing: A Comparative Analysis of Official Tourism Boards
}

Rashmiranjan Choudhury* and Priyakrushna Mohanty ${ }^{\dagger}$

\section{Abstract}

Marketing has reached new heights with social media platforms. In the changing scenario of the service industry, tourism is seen to receive the most attention from customers, stakeholders and other sectors through social media. The development of communication technology has enriched social media marketing. In India, Facebook has taken a lead role because of its market outreach and user count. Different tourism associates use this medium to showcase their products and services. In this context, Kerala is way ahead in social media marketing strategies while Odisha is in the niece states. This paper aims to analyse the social media marketing strategies adopted by the Odisha tourism board and other tourism boards through a comparative analysis. The study suggests some strategic measures for Odisha tourism board to ensure the effective use of social media in tourism.

Keywords: Social Media, Tourism Marketing, Odisha Tourism, Kerala Tourism, Marketing Strategy, Comparative Study, Facebook

\section{Introduction}

Technological developments bring about a revolution in human life. Among the revolutions, the internet has become one of the

\footnotetext{
North-Eastern Hill University, Shillong, Meghalaya, India; rrcrashmiranjan@gmail.com

† Pondicherry University, Pondicherry, India; pkmohanty90@gmail.com
} 
essential requirements in the present world. The tourism industry has observed an identical change in information access, tour planning, and bookings as well as in tour experience sharing through the internet (Buhalis \& Law, 2008; Xiang \& Gretzel, 2010). In the digital era, the internet has influenced communication through virtual mediums or online social networking. In the present times, information is spread faster through the Social Networking Sites (SNS) than any other media. Hence, tourism establishments, destination marketing organisations (DMOs) or official tourism boards promote tourism by using various strategies through SNS. Social media not only presents the information to the outer world but also increases the reliability of the organisation. Studies reveal that 'social media review' acts as an important aspect of the electronic word of mouth (e-women) and plays a vital role in the customer's decision-making process (Litvin, Goldsmith, \& Pan, 2008; Tham, 2013). Several business entities use social media as marketing tools for products as well as services (Rosemary, Martinette, \& Melville, 2016; Roque \& Raposo, 2016; Fatimah \& Murphy, 2010). Hence, with a significant stance in tourism marketing, social media cannot be overlooked. From the last decade, the popularity of the internet has grown in India, escalating social media to the next level. Among various SNS, Facebook is the most accepted social network with 251 million active users in India (Internet World Stats, 2018).

The information search trend in India suggests that the popularity of Kerala tourism has been higher than other tourism boards in the last year (Google Trends, 2018). Through better social media posting, user engagement, and planned management, the official Facebook page of Kerala tourism has become the best tourism page in India (Bobins, 2018). In social media marketing, the Odisha tourism board is at a niche stage as compared to the social media penetration. This paper is an attempt to study the social media status and strategies adopted by the Odisha tourism board. Through a comparative analysis with the developed Kerala tourism board in India, the study narrates the complications of the Odisha tourism board and suggests corrective measures to overcome their shortcomings. 


\section{Study Objective}

The title of the study is well directed towards the objectives. The paper focusses on three major objectives. The primary objective is to study the social media marketing strategy of Kerala tourism, the most developed tourism board in India. Secondly, the paper attempts to analyse the present status of Odisha tourism through a comparative analysis with the social media marketing strategy of Kerala tourism. The third and final objective of the paper is to suggest appropriate strategies and monitoring measures for better marketing of Odisha tourism through social media.

\section{Review of Literature}

\subsection{Social media and tourism marketing}

Technology has revitalised the business environment and has taken it to the next level with the effective use of social media in different aspects. In the new era, the two-way communication of information provides flexibility to the consumer society in presenting their thoughts, inquiring for services, and providing suggestions. With the new technology of Web 2.0, social media directs users to create content, initiate, and circulate them on the internet. This further leads to online social networking of a specific group of people, making one another aware about different issues, and helping each other in choosing from different products and services (Chauhan \& Pillai, 2013; Wang, Yu, \& Fesenmaier, 2002). Online social media is a dynamic platform which is participatory and conversational in nature. It has different elements that create a virtual community with people with a common purpose, commanded by certain unwritten policies that run through the computer system (Wang, $\mathrm{Yu}$, \& Fesenmaier, 2002; Buhalis \& Law, 2008). The bi-directional engagement of customers and business entities make social media an important element of the marketing mix (Mangold \& Fauld, 2009).

Social media refers to activities, practices, and behaviours among communities of people who gather online to share information, knowledge, and opinions using conversational media. Conversational media are web-based applications 
that make it possible to create and easily transmit content in the form of words, pictures, videos, and audios". (Brake \& Safko, 2009; Hays, Page, \& Buhalis, 2012)

The two forms of social media communication namely the firmbased and user-generated have overcome the traditional media of communication (Schivinski \& Dabrowski, 2016; Mangold \& Fauld, 2009). In firm-based social media communication, companies and business organisations have control over contents, engage consumers, influence costumer's perception and knowledge about their audience (Schivinski \& Dabrowski, 2016; Brodie, Ilic, Juric, \& Hollebeek, 2013). TripAdvisor and Lonely Planet are the most important social networking mediums that provide information about hotels around the world and bring consumers to a single discussion forum (Buhalis \& Law, 2008). The user-generated contents (UGC) on social media is the most effective communication medium where user count is more and the penetration field is larger as compared to the previous one. In this medium, content is created, circulated, and managed by the user without any commercial intentions and communication takes place directly between the consumers (OECD, 2007; Schivinski \& Dabrowski, 2016). UGC accelerates the communication. This plays an important role in branding, customer retention, and positioning. Facebook, Twitter, Google+ Youtube are the mostly used UGC social media platforms for the communication of information where users share their own experience, thoughts suggestions and so on (Chung \& Koo, 2015).

Intangible in nature, the service industry tourism is very sensitive towards information. Customers gather information from different sources including online social media for planning their trips, choosing destinations, accommodations and restaurant services (Chung \& Buhalis, 2008). Online travel reviews and user-generated contents on social media seem to be more reliable. This influences the behaviour of potential customers (Munar, 2012). 


\begin{tabular}{ll}
\hline \multicolumn{2}{c}{ Examples of types of online social media } \\
\hline Media-sharing sites & Flickr, YouTube \\
Blogging & Travelblog \\
Microblogging & Twitter \\
Review sites & TripAdvisor \\
Social bookmarking and voting sites & Digg \\
Social networking sites & Facebook, LinkedIn \\
\hline
\end{tabular}

(Munar, 2012)

The advantages of marketing of tourism in social media are costeffectiveness, massive reach, engagement of customers, free platform, and user-friendliness. Apart from the traditional approach, social media marketing takes a comprehensive role in the tourism industry. Tourism organisations that do not adopt social media will lack a competitive advantage in the market (Wang, Yu, \& Fesenmaier, 2002; Stankov, Lazic, \& Dragicevic, 2010). Creating brand awareness or branding, building a community and customer engagement are the basic objectives of social media marketing. As the spread of social networks is large and mixed in nature, some challenges like difficulty in content creation and supervision, measuring social media success, time management and so on crop up time and again (Surevin BPO service Ltd, n.d.). Hence, understanding the social media platforms, choosing the right target audience, measuring effectiveness and interlink with tourism becomes more important for tourism organisations (Hays, Page, \& Buhalis, 2012).

Information representation is the major aspect of social media with collaboration and interactive communication with other media. Tourism organisations' contents on social media are majorly categorised as tourist destination information, promotion of events (centred on tourism), advertising offers to attract more customers, promoting own website and marketing other's website and so forth.

\subsection{Social media in India}

In India, the internet revolution started during the first decade of the twenty-first century when the use of computers and the internet gained popularity. After 2010, when the smartphone revolution and mobile data competency occurred in India, a massive growth was seen in mobile and internet users. In the global market of 
smartphone users, India was seen to have the highest number of Android smartphone users (Chaturvedi \& Aulakh, 2018).

Indians spend on an average, 200 minutes on the mobile internet from which 70 percent is spent on social media. Facebook, Instagram and WhatsApp are popular social networking applications in India which take 38 percent of the time in everyday use (Pillai, 2017). According to its last year Quarter Two reports, Facebook had 217 million monthly active users in India (Chaturvedi \& Aulakh, 2018). The number of users rose to 251 million in December 2017 with a rising rate of 18.5 percent (Internet World Stats, 2018).

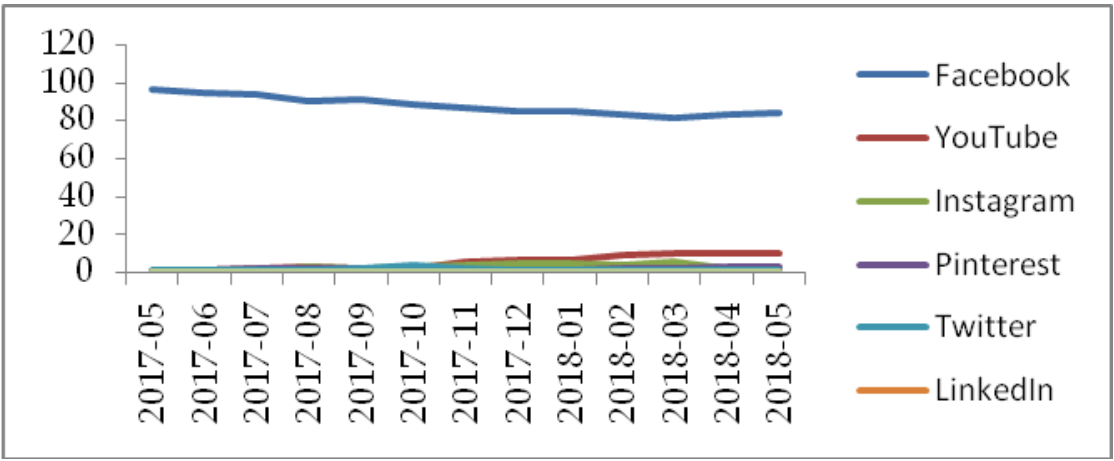

Fig 1 Social Media popularity in India, (Source: Stat counter Global Stats)

In social media penetration and popularity, Facebook takes the leading role with 84 percent popularity among other social media in India. The tourism industry gets a better response on Facebook as information spreads faster. Kerala tourism uses Facebook much more than other tourism boards and has been ranked as the best Facebook page for the year 2017. This present study emphasises the effective use of social media in tourism marketing and development by different state tourism boards in India.

\section{Data and Methodology}

From the literature review, it is revealed that little study has been conducted on social media usage in the tourism industry in India thereby identifying a considerable gap in understanding the use of social media for promotion and branding of the tourist destinations 
by the official tourism boards. The study is designed as an exploratory one with the help of both primary and secondary data. A comparative approach is adopted to study the effectiveness and experiences of developed tourism boards and to learn strategies from them (Hays, Page, \& Buhalis, 2012).

The primary data is retrieved from the social media web page of concerned tourism board by analysing the contents over a period of six months (January-June, 2018). As the leading social media in India, Facebook is chosen as a medium for the study. Views, followers, likes, comments, and shares were considered as content responses and logically presented in the study. Secondary data and materials were collected from various online and offline sources like books, journal articles, news reports as well as from different relevant web contents. The collected data were analysed through content analysis and framed in a sequentially logical manner.

\section{Findings, Analysis and Discussion}

\subsection{Viewers count in official social media page}

In Facebook social media, 'like and share' is regarded as a marker of the popularity of the content. The more the page is liked, the more are the number of page viewers. This further adds to other contexts such as post likes, post shares and so on. When new posts come to Facebook, the ones who have liked or followed those particular pages can view those posts. On the home page, the information displays the popularity of the concerned page and attracts users to rely on the available contents of the page.

Table 1 Tourism board's official Facebook page statistics; data up to $15^{\text {th }}$ July 2018

\begin{tabular}{ccccc}
\hline $\begin{array}{c}\text { Tourism } \\
\text { Boards }\end{array}$ & Official Facebook page & $\begin{array}{c}\text { Member } \\
\text { since }\end{array}$ & $\begin{array}{c}\text { Page } \\
\text { liked }\end{array}$ & $\begin{array}{c}\text { Page } \\
\text { followers }\end{array}$ \\
\hline Odisha & facebook.com/ Odisha & December & & \\
Tourism & Tourism Official & 2014 & 232,604 & 233,355 \\
Kerala & facebook.com/ & January & & \\
Tourism & keralatourismofficial & 2010 & $1,516,881$ & $1,509,466$ \\
\hline
\end{tabular}

(Source: Official Facebook page of concerned tourism board) 
Table 1 data shows that the popularity of Kerala tourism in social media is way ahead of Odisha tourism. The number of followers of Odisha tourism is higher than the page likes. This indicates that the users want to follow the content but do not opt to like the page. Though these users are important for the page, the number count limits the page popularity.

\subsection{Post relevancy and response:}

The posts pertaining to the organisation's goals are considered relevant posts on Facebook. A post with audio-visual or photo content brings more attention than textual posts and keeps the post active for a longer period.

Table 2 Tourism board's official Facebook page contents (Jan-June 2018); data up to $15^{\text {th }}$ of July 2018

\begin{tabular}{lcc}
\hline Contents on Official Facebook page & Odisha tourism & Kerala Tourism \\
\hline Posts in Timeline & 151 & 398 \\
Photos in posts & 171 & 303 \\
Videos in posts & 33 & 113 \\
Posts linked/shared to the page & 32 & 85 \\
Posts shared from the page & 12,337 & 28,963 \\
Likes of posts in timeline & 78,598 & 241,127 \\
\hline
\end{tabular}

The number of posts published through Facebook pages by the Kerala tourism board is much higher than the Odisha tourism. The average number of posts per month for Odisha Tourism is 25.16 compared to 66.33 of Kerala Tourism. Kerala Tourism aims to publish more content on a regular basis to engage the users and to attract more users to the page.

\subsection{Post frequency}

Frequent posting and updated information keep the users engaged on the social media page. Studies suggest that the number of posts on a Facebook page should not exceed 10 posts per week and two posts a day (Andrew, 2018; Daria, 2017) for effective presentation of information and response management. Observing the insights on Facebook pages, understanding users' preferences along with trends and responses can be useful for publishing content. According to Prateek (2017) and Nathan (2017), the best time to 
publish content on Facebook is between $1 \mathrm{pm}$ to $4 \mathrm{pm}$. They also suggest avoiding late night and early morning posts on social media.

Figure 2 demonstrates the irregular content published on the Facebook page by Odisha Tourism as compared to the more often published posts by Kerala tourism. In the month of January, users found a notable number of posts but a massive fall in the next consecutive months which went to the lowest number of posts in the month of April.

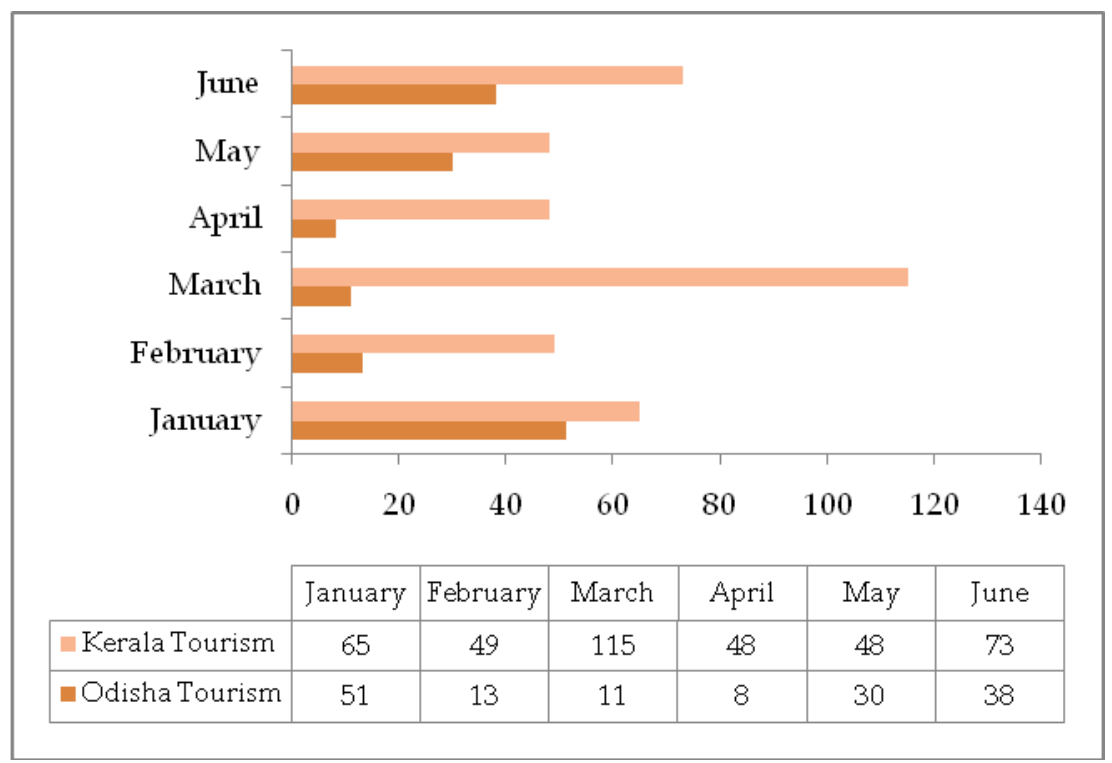

Fig 2 Month wise distribution of posts on Facebook page; Source: Official Facebook page of concerned tourism board (Jan-June 2018); data up to $15^{\text {th }}$ July 2018

In user engagement and information publication, Odisha tourism is way behind not only from Kerala but also from other state tourism boards. The average posts per day for Odisha tourism board is 0.83 which indicates that on some days there are no posts on the Facebook timeline whereas the average posts of Kerala tourism board is 2.21 thereby showing the regularity of information posting. The Kerala tourism page gets at least one post every day and on some occasions, the count goes higher, keeping the page users engaged as well as attracting new users. 


\subsection{Posts' content type}

On the Facebook social media page, diversities of contents are posted keeping in mind the purpose of the organisation, preference of the audience and information updating.

Table 3 Distribution of post according to contents; data up to $15^{\text {th }}$ July 2018

\begin{tabular}{lcc}
\hline \multicolumn{1}{c}{ Type of Contents } & Odisha Tourism & Kerala Tourism \\
\hline Tourist Destination Information & 48 & 128 \\
Tourism Culture promotion & 15 & 94 \\
Tourism related Events & 17 & 64 \\
$\begin{array}{l}\text { Own and others' website } \\
\text { information }\end{array}$ & 30 & 59 \\
$\begin{array}{l}\text { Other posts (Awareness, Awards, } \\
\text { Wishes, etc.) }\end{array}$ & 12 & 10 \\
\hline
\end{tabular}

\section{Odisha Tourism Board}
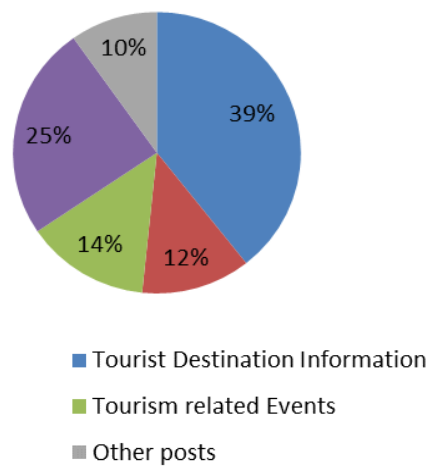

- Tourist Destination Information

Tourism related Event

Other posts

\section{Kerala Tourism Board}

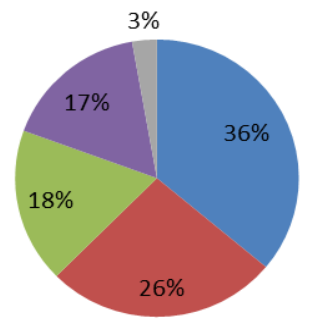

- Tourism Culture Information

- Own and others' website information

Fig 3 Content type Source: official Facebook page of concerned tourism board (Jan-June 2018); data up to $15^{\text {th }}$ July 2018

Figure 3 illustrates that both the tourism boards share destination related posts more frequently and their numbers are comparatively more than other contents. Odisha tourism board and Kerala tourism board shares $39 \%$ and $36 \%$ of destination related contents in the survey period respectively. Though Odisha is a land of diversified culture, the cultural content count is $(12 \%)$ less than 
other segments in Odisha tourism board Facebook page. Culture is as important as a destination for the promotion of any tourism organisation hence Kerala board shares a substantial number $(26 \%)$ of cultural posts on their Facebook page.

Events in tourism are platforms for the promotion of the region and they provide an opportunity for tourists to engage and experience the unique culture and promote the destination to a larger extent. Tourism-related events are celebrated in Odisha throughout the year but only a selected number of events are promoted through the official social media. The Odisha tourism board shares only 17 events on the Facebook page, which counts to $14 \%$ of all contents whereas $18 \%$ of contents (64 in number) of Kerala tourism gains better response on social media. Regional events like Dhanu Yatra (Baragarh district), Folk Dance Festival (Sambalpur), Tribal Fair at Bhubaneswar and Chhow Festival (Mayurbhanja) with enormous tourism importance were not promoted on the official social media page.

Information from other web portals is linked to social media pages to present the information effortlessly. In most cases, the linked posts get less response from the users as the link directs the user to another webpage. 17 percent of the posts of the Kerala tourism board are alien, whereas Odisha tourism board posts around 25 percent posts linked to other web portals. A larger share of inept posts like wishes and public news also diminish the page relevance of the Odisha tourism board in social media.

Through social media promotion, each segment needs to be addressed with equal importance. Moreover, the tourism events carry cultural values and promote the destination also. A better promotion of a tourism event can improve the reliability of the social media page. Hence Odisha tourism board needs to postcultural and event-related posts along with the promotional destination posts. The unproductive shared posts and unfamiliar posts should be limited to ensure the better presentation of the social media page.

\subsection{Social media interlink}

Different social media platforms and contents do not appear the same. Hence, by interlinking different mediums by the post-share 
option, marketing goals can be achieved effectively. One video post 'Welcome to 2018 the kurinji year' shared from the Youtube official page to the Facebook page of Kerala tourism raises the credibility of both the social media platforms. Published contents from Twitter, Instagram, and Flicker can be shared using post sharing options to publish effectively and efficiently on Facebook. The social media interlink provides a wider audience which also keeps the post alive for a longer period of time. In the Odisha tourism Facebook social media page, a lesser number of posts are linked to other social media and vice versa.

\subsection{Reflection of the social media link}

Adding a social media link to the official websites helps to bring more traffic to social media pages as users search for more information apart from the available ones on the website and most of the time they follow the social media reviews (Munar, 2012). The social media button should be placed in the header or footer. It is most effective when placed in the sidebar using the updated button (Mallory, 2012). In the official website of Odisha Tourism, the social media button is placed at the bottom of the page which may not be marked by website visitors more often.

\subsection{Suggestion}

Though Odisha tourism is active on social media, some corrective measures need to be adopted for better presentation in the fast moving internet world. They are:

- Posts must be published frequently on social media to keep the users engaged. This will further attract new users. Importance must be given to destination posts as well as event and culture related posts.

- Advanced social media technologies, like 360 Photo, Live video, hashtag (\#tag) must be used

- The Unique Selling Proposition (USP) in the photo or video posts to gain the attention of maximum users must be highlighted

- The 'Promote your page' option available on Facebook should be used to reach more viewer promoted pages 
- A tourism event should be promoted before it happens. Also, advertising through social media and providing viewers with entry passes or access to the event can be useful. Maximum users are active during the event. Therefore, information conveyed through audio-visual modes will keep viewers engaged and also attract new ones. Follow-up reviews after the event is equally important to distinguish the user demands

- Registered tour operators and hotel industries must be encouraged to promote the official social media page rather than creating new pages

\section{Conclusion}

Social media marketing has had a greater influence on tourism marketing. However, proper strategies need to be followed by the institute. Odisha as a tourism destination has great potential but falters in the way it presents information on social media. Therefore, the social media page has not achieved the desired popularity. The primary objective thus should be to reach out to more social media users which must reflect on the page. The comparative analysis suggests that the Odisha tourism page missed out on content publishing frequency and event promotion. A consistent analysis of the social media data can provide appropriate suggestions on the social networking trends for better management of the page. To conclude, it is the responsibility of the regional social media users to spread the reach of Odisha tourism to the global arena thereby marking Odisha as an elegant tourism destination.

\section{Reference}

Andrew, H. (2018). Facebook Now lists page posting frequency in search results. Retrieved from https://www.socialmediatoday.com/news/ facebooks-now-listing-page-posting-frequency-in-searchresults/513906/

Bobins, A. (2018). Facebook ranks Kerala tourism page as best in the country in 2017. Retrieved from https:// www.indiatimes.com/ news/ india/ 
facebook-ranks-kerala-tourism-page-as-best-in-the-country-in-2017_345665.html

Brake, D., \& Safko, L. (2009). The social media Bible. Hoboken: John Wiley and Sons, Inc.

Brodie, R., Ilic, A., Juric, B., \& Hollebeek, L. (2013). Consumer engagement in a virtual brand community: An exploratory analysis. Journal of Business Research, 66(8), 105-114.

Buhalis, D., \& Law, R. (2008). Progress in information technology and tourism management: 20 years on and 10 years after the Internet-The state of eTourism research. Tourism Management, 29(4), 609-623.

Chaturvedi, A., \& Aulakh, G. (2018). Indian social media users more prone to data breach. Delhi, New Delhi, India.

Chauhan, K., \& Pillai, A. (2013). Role of content strategy in social media brand communities: a case of higher education institutes in India. Journal of Product \& Brand Management, 1(22), 40-51.

Chung, J., \& Buhalis, D. (2008). Information needs in online social networks. Information Technology \& Tourism, (10), 267-281.

Chung, N., \& Koo, C. (2015). The use of social media in travel information search. Telematics and Informatics, (32), 2015-229.

Daria, M. (2017, September 17). How frequently should I publish on social media? A hubspot experiment. Retrieved from https://blog.hubspot.com/marketing/how-frequently-should-ipublish-on-social-media

Fatimah, S.-A. S., \& Murphy, J. (2010). Social networking as a marketing tool: the case of a small Australian company. Journal of Hospitality Marketing \& Management, 19(7), 700-716.

Google Trends. (2018). Compare. Retrieved from https://trends.google.com/trends/explore?cat $=67 \&$ geo $=I N \& q=O d i s$ ha\%20tourism,Kerala\%20tourism,Tamil\%20Nadu\%20Tourism,Gujara t\%20Tourism

Hays, S., Page, S. J., \& Buhalis, D. (2012). Social media as a destination marketing tool: its use by national tourism organisations. Current Issues in Tourism, 16(3), 211-239.

Internet World Stats. (2018). Retrieved from https:// www.internetworldstats.com/asia.htm\#in

Litvin, S. W., Goldsmith, R. E., \& Pan, B. (2008). Electronic word-of-mouth in hospitality and tourism management. Tourism Management, 29(3), 458-468. 
Mallory, W. (2012). 9 tips for integrating social media on your website. Retrieved from https://www.socialmediaexaminer.com/9-tips-forintegrating-social-media-on-your-website/

Mangold, W. G., \& Fauld, D. J. (2009). Social media: The new hybrid element of the promotion mix. Business Horizons, 52(4), 357-365.

Munar, A. M. (2012). Social media strategies and destination management. Scandinavian Journal of Hospitality and Tourism, 12(2), 101-120.

Nathan, E. (2017). How often to post on social media? Retrieved from https://coschedule.com/blog/how-often-to-post-on-social-media/

OECD. (2007). Participative Web and User-Created Content: Web 2.0 Wikis and Social Networking. OECD Publishing, Paris, https://doi.org/10.1787/9789264037472-en

Pillai, S. (2017). Indians spend $70 \%$ of mobile internet time on social media, entertainment. The Times of India. Retrieved from https:/ / timesofindia.indiatimes.com/business/india-

business/indians-spend-70-of-mobile-internet-time-on-socialentertainment/articleshow /62125840.cms

Prateek, K. (2017). Best times and frequency to post on Facebook, Twitter, and Instagram. Retrieved from https://blog.markgrowth.com/best-timesand-frequency-to-post-on-facebook-twitter-and-instagram33d5e7210a25

Roque, V., \& Raposo, R. (2016). Social media as a communication and marketing tool in tourism: An analysis of online activities from international key player DMO. Anatolia, 27(1), 58-70.

Rosemary, M., Martinette, K., \& Melville, S. (2016). The usage of social media as a marketing tool in two Southern African countries. Development Southern Africa, 33(5), 740-755.

Schivinski, B., \& Dabrowski, D. (2016). The effect of social media communication on consumer perceptions of brands. Journal of Marketing Communications, 22(2), 189-214.

Stankov, U., Lazic, L., \& Dragicevic, V. (2010). The extent of use of basic Facebook user-generated content by the national tourism organizations in Europe. European Journal of Tourism Research, 3(2), 105-113.

Statcounter GlobalStats. (n.d.). Retrieved from http://gs.statcounter.com/social-media-stats/all/india

Surevin BPO service Ltd. (n.d.). 11 Impressive Social Media Marketing Insights in India Retrieved from http://www.surevin.com/11impressive-social-media-marketing-insights-in-india/ 
Tham, A. (2013). Social media in destination choice: distinctive electronic word-of-mouth dimensions. Journal of Travel \& Tourism Marketing, 30(1-2), 144-155.

Wang, Y., Yu, Q., \& Fesenmaier, D. R. (2002). Defining the virtual tourist community: implications for tourism marketing. Tourism Management, 23(4), 407-417.

Xiang, Z., \& Gretzel, U. (2010). Role of social media in online travel information search. Tourism Management, 31(2), 179-188. 